\title{
Comment on "Hysteropreservation versus hysterectomy in the surgical treatment of uterine prolapse: systematic review and meta-analysis"
}

\author{
Shveta $\operatorname{Kapoor}^{1}{ }^{1}$ - Kanapathippillai Sivanesan ${ }^{1}$. \\ Vishal Kapoor $^{2} \cdot$ Mayooran Veerasingham $^{1}$
}

Received: 26 August 2017 / Accepted: 11 September 2017 /Published online: 18 September 2017

(C) The International Urogynecological Association 2017

Sir,

We read with great interest the review article by de Oliveira et al. entitled "Hysteropreservation versus hysterectomy in the surgical treatment of uterine prolapse: systematic review and meta-analysis" [1]. First, we congratulate the authors on a well-conducted systematic review on this very pertinent topic. Broadly, the results are in agreement with those of other systematic reviews comparing uterus-preserving prolapse repair procedures with vaginal hysterectomy [2].

We wonder why the authors did not include the large randomized controlled trial by Detollenaere et al. of vaginal sacrospinous hysteropexy versus vaginal hysterectomy with uterosacral ligament suspension [3]. This randomized controlled trial with over 100 women in each arm would meet the inclusion criteria of the current review and add strength to the evidence. Inclusion of data from this study in the current metaanalysis for the subgroup 'vaginal hysteropexy vs. vaginal hysterectomy - no mesh' would change the relative risk for recurrence from 3.70 (95\% confidence interval 1.11-12.37) to 1.41 (95\% confidence interval 0.21-9.30). This result, showing no difference in recurrence rates between the two procedure, would align with the results of our meta-analysis comparing sacrospinous hysteropexy and vaginal hysterectomy [4].
Compliance with ethical standards

Conflict of interest The authors declare that they have no conflict of interest.

\section{References}

1. de Oliveira SA, Fonseca MCM, Bortolini MAT, Girão MJBC, Roque MT, Castro RA. Hysteropreservation versus hysterectomy in the surgical treatment of uterine prolapse: systematic review and meta-analysis. Int Urogynecol J. 2017. https://doi.org/10.1007/s00192-0173433-1.

2. Maher C, Feiner B, Baessler K, Christmann-Schmid C, Haya N, Brown J. Surgery for women with apical vaginal prolapse. Cochrane Database Syst Rev. 2016;10:CD012376.

3. Detollenaere RJ, den Boon J, Stekelenburg J, IntHout J, Vierhout ME, Kluivers KB, et al. Sacrospinous hysteropexy versus vaginal hysterectomy with suspension of the uterosacral ligaments in women with uterine prolapse stage 2 or higher: multicentre randomized non-inferiority trial. BMJ. 2015;351: h3717.

4. Kapoor S, Sivanesan K, Robertson JA, Veerasingham M, Kapoor V. Sacrospinous hysteropexy: review and meta-analysis of outcomes. Int Urogynecol J. 2017;28(9):1285-94. https://doi.org/10.1007/ s00192-017-3291-x.

An author's reply to this comment is available at https://oi.org/10.1007/ s00192-017-3494-1.

Shveta Kapoor

drshvetakapoor@yahoo.co.in

1 Ipswich Hospital, QLD Health, University of Queensland, Chelmsford Avenue, Ipswich, QLD 4305, Australia

2 Lady Cilento Children's Hospital, QLD Health, University of Queensland, St Lucia, Australia 